\title{
In-Situ Catalytic Fast Pyrolysis Technology Pathway
}

Mary Biddy and Abhijit Dutta National Renewable Energy Laboratory

Susanne Jones and Aye Meyer Pacific Northwest National Laboratory

NREL is a national laboratory of the U.S. Department of Energy, Office of Energy Efficiency \& Renewable Energy, operated by the Alliance for Sustainable Energy, LLC, under contract DE-AC36-08G028308.

Pacific Northwest National Laboratory is operated by Battelle for the United States Department of Energy under contract DE-AC05-76RL01830.

Technical Report

NREL/TP-5100-58056

PNNL-22320

March 2013

Prepared for the U.S. Department of Energy Bioenergy Technologies Office 


\section{In-Situ Catalytic Fast Pyrolysis Technology Pathway}

Mary Biddy and Abhijit Dutta National Renewable Energy Laboratory

Susanne Jones and Aye Meyer Pacific Northwest National Laboratory

NREL is a national laboratory of the U.S. Department of Energy, Office of Energy Efficiency \& Renewable Energy, operated by the Alliance for Sustainable Energy, LLC, under contract DE-AC36-08G028308.

Pacific Northwest National Laboratory is operated by Battelle for the United States Department of Energy under contract DE-AC05-76RL01830.

Technical Report

NREL/TP-5100-58056

PNNL-22320

March 2013

Prepared for the U.S. Department of Energy Bioenergy Technologies Office

National Renewable Energy Laboratory 15013 Denver West Parkway Golden, Colorado 80401 303-275-3000 • www.nrel.gov
Pacific Northwest National Laboratory P.O. Box 999

Richland, WA 99352

1-888-375-7665 - www.pnl.gov 


\section{NOTICE}

This report was prepared as an account of work sponsored by an agency of the United States government. Neither the United States government nor any agency thereof, nor the Alliance for Sustainable Energy, LLC, nor Battelle Memorial Institute, nor any of their employees, makes any warranty, express or implied, or assumes any legal liability or responsibility for the accuracy, completeness, or usefulness of any information, apparatus, product, or process disclosed, or represents that its use would not infringe privately owned rights. Reference herein to any specific commercial product, process, or service by trade name, trademark, manufacturer, or otherwise does not necessarily constitute or imply its endorsement, recommendation, or favoring by the United States government or any agency thereof. The views and opinions of authors expressed herein do not necessarily state or reflect those of the United States government or any agency thereof, or the Alliance for Sustainable Energy, LLC, or Battelle Memorial Institute.

Available electronically at http://www.osti.gov/bridge

Available for a processing fee to U.S. Department of Energy and its contractors, in paper, from:

U.S. Department of Energy

Office of Scientific and Technical Information

P.O. Box 62

Oak Ridge, TN 37831-0062

phone: 865.576 .8401

fax: 865.576.5728

email: mailto:reports@adonis.osti.gov

Available for sale to the public, in paper, from:

U.S. Department of Commerce

National Technical Information Service

5285 Port Royal Road

Springfield, VA 22161

phone: 800.553 .6847

fax: 703.605.6900

email: orders@ntis.fedworld.gov

online ordering: http://www.ntis.gov/help/ordermethods.aspx

Printed on paper containing at least $50 \%$ wastepaper, including $10 \%$ post consumer waste. 


\section{In-Situ Catalytic Fast Pyrolysis}

\section{Developing Technology Pathway Cases to Understand the Cost of Converting Biomass to Hydrocarbon Fuels}

In support of the Bioenergy Technologies Office, the National Renewable Energy Laboratory (NREL) and the Pacific Northwest National Laboratory (PNNL) are undertaking studies of biomass conversion technologies to hydrocarbon fuels to identify barriers and target research toward reducing conversion costs.

Process designs and preliminary economic estimates for each of these pathway cases were developed using rigorous modeling tools (Aspen Plus and Chemcad). These analyses incorporated the best information available at the time of development, including data from recent pilot- and bench-scale demonstrations, collaborative industrial and academic partners, and published literature and patents. The economic results of these analyses are in the process of further refinement and will be published in FY13 and FY14 design reports. This report summarizes the preliminary technical data used for the models and identified data gaps.

This technology pathway case investigates converting woody biomass using in-situ catalytic fast pyrolysis followed by upgrading to gasoline-, diesel-, and jet-range hydrocarbon blendstocks. Technical barriers and key research needs that should be pursued for this pathway to be competitive with petroleum-derived blendstocks have been identified.

\section{Process Block Diagram}

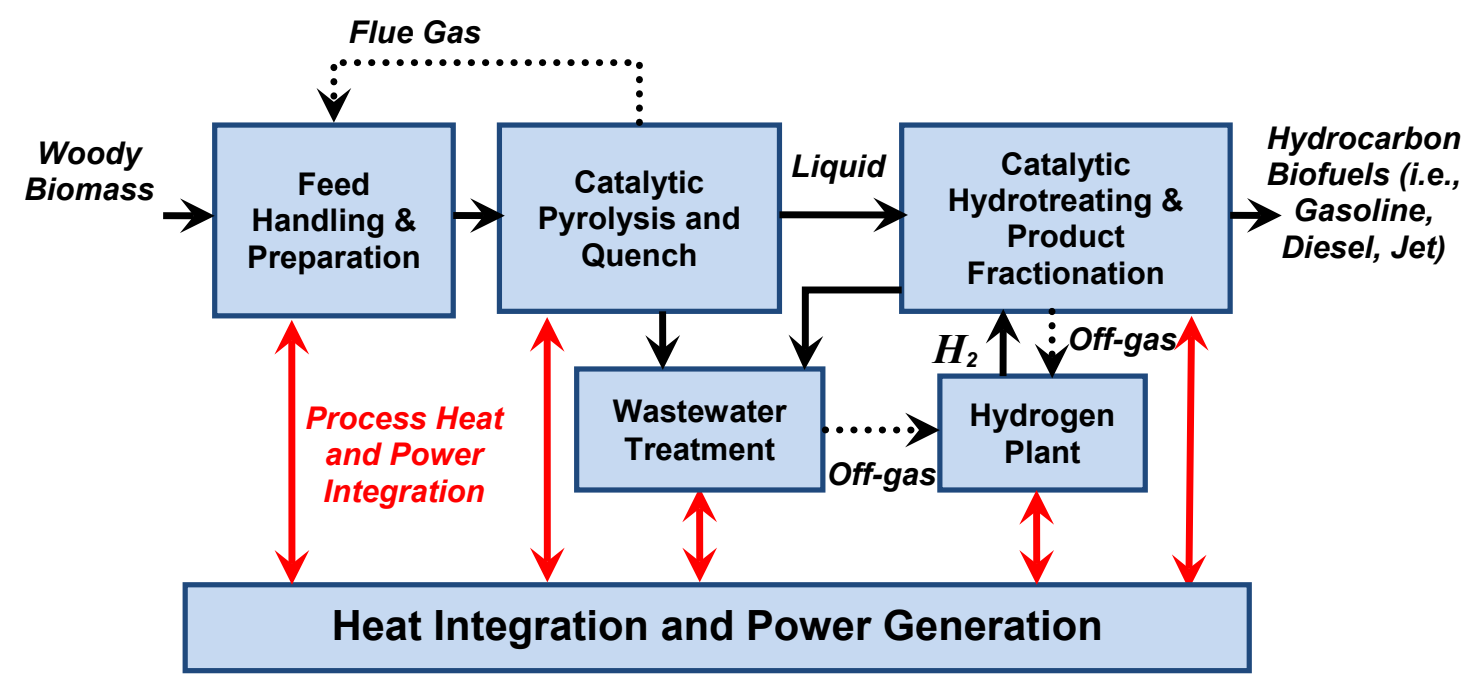

\section{Key Highlights}

- In-situ vapor phase catalytic upgrading of fast pyrolysis vapors combines direct liquefaction of biomass by pyrolysis and pyrolysis vapor upgrading in the same vessel.

- In-situ catalytic pyrolysis has the potential to reduce costs associated with upgrading conventional fast pyrolysis oil to a hydrocarbon by producing a lower-oxygen-content 
intermediate phase with lower associated water. Hydrogen consumption during final upgrading to a hydrocarbon will also be reduced.

- The addition of the vapor phase upgrading catalyst to the same reactor that pyrolyzes the biomass eliminates the external vapor phase reactor (ex-situ vapor phase upgrading), thus likely reducing capital and operating costs.

- The upgraded vapor's lower reactivity may allow use of extended surface heat exchangers to recuperate heat and reduce the cooling water load when the vapors are condensed.

- Important research needs for this pathway include developing catalysts with improved yields, stability, and lifetimes, maximizing overall conversion to the desired hydrocarbon product, optimizing CFP oil hydrotreating, and developing economic wastewater treatments.

\section{Process Design Details}

Feed handling: Woody biomass is dried to approximately $10 \mathrm{wt} \%$ moisture and finely ground to 2-6 mm. Waste heat streams from the pyrolysis section are used to dry the biomass. Drying and grinding costs are included in the feedstock costs (Jones and Male 2012).

Catalytic fast pyrolysis: The model is based on a process consisting of a catalyst-containing circulating fluidized bed pyrolysis reactor, cyclones, and a combustor. Biomass is contacted with hot catalyst (and possibly a heat carrier) and fluidizing gas in a short residence time pyrolysis reactor at $\sim 500^{\circ} \mathrm{C}$ and atmospheric pressure in the absence of air. Biomass is converted to condensable vapors and non-condensable gas, char, and coke. The evolved vapors are catalytically converted to less reactive compounds than those produced by uncatalyzed fast pyrolysis. Char and catalyst are separated from the vapor in cyclones and sent to a combustor to burn the char and any coke on the catalyst. This also serves to reheat the catalyst, which is returned to the pyrolysis reactor. Cyclones by themselves do not completely remove particulates from the product. Effective solids removal from the products is necessary to protect downstream equipment. This could be done, for example, by hot filtration of the vapor product prior to quenching or cold filtration of the liquid products. The pyrolysis vapors leaving the cyclone are condensed by heat recovery and trim cooled. Non-condensable gases are removed and two liquid phases are formed. The predominately organic phase is sent to hydrodeoxygenation and the predominately aqueous phase is routed to water treatment.

Oxygen content of the organic phase and carbon content of the aqueous phase are dependent upon reaction time, temperature, and catalyst type. Yields are based on laboratory-scale experimental results for vapor phase upgrading (Dayton 2011a; Dayton 2011b). In-situ catalyst usage was not called out in these references. The $\mathrm{n}^{\text {th }}$ plant cost model assumes two parallel catalytic pyrolyzers each processing 1,000 dry metric tonnes per day (tpd) of dry biomass.

Catalytic hydrodeoxygenation: Catalytic pyrolysis oil is combined with hydrogen at $255^{\circ}-$ $410^{\circ} \mathrm{C}$ and $\sim 2,000 \mathrm{psi}$ and is converted to hydrocarbon, water, and gas over a fixed bed reactor. Depending upon the reactivity of the catalytic pyrolysis oil, two beds may be needed. The first bed is operated at the lower end of the temperature range to further reduce any remaining highly reactive compounds. The second bed is operated at the higher end of the temperature range, and 
possibly at a lower space velocity to allow complete deoxygenation. The ideal goal is that the catalytic pyrolysis oil is of high enough quality so that only a single hydrotreater is needed. After cooling, the products are separated and the hydrocarbon product is distilled into $\mathrm{C}_{4}$ minus, gasoline range, and diesel range material. The targeted oxygen content of the upgraded oil is $<1$ $\mathrm{wt} \%$. The cost model assumes that the product quality is sufficiently suitable for gasoline and diesel blendstocks. Wastewater is assumed to have $<1 \mathrm{wt} \%$ carbon. The process model is based on experimental conditions and hydrodeoxygenation conversion for catalytic pyrolysis oil (Dayton 2011b; Zacher et al. 2011) and conventional pyrolysis oil (Elliott et al. 2009). The flow scheme is based on the upgrading section of the PNNL pyrolysis design case (Jones et al. 2009).

Hydrogen plant: Off-gases from the catalytic pyrolysis reactor, from the hydrodeoxygenation section, and from wastewater treatment are sent to a conventional hydrogen plant consisting of a steam reformer, water gas shift reactor, pressure swing adsorption unit, and heat recovery. Supplemental natural gas is not needed to satisfy the hydrogen demand based on the modeled results and the assumed level of catalytic pyrolysis oil oxygen content. No processing penalty is assumed for using off-gas in place of natural gas as reformer feed; this may be optimistic. The hydrogen plant size is within typical commercial scale. Design conditions are based on commercial-type systems running on natural gas (SRI Consulting 2007). Alternately, the fluidized bed reformer system developed for steam reforming of biomass syngas for the 2012 ethanol demonstration (Dutta et al. 2011) can be used as the reformer for this process.

Wastewater treatment: The aqueous phase from catalytic pyrolysis likely contains acids, aldehydes, and phenolics. As no data yet exist for this treatment, it is assumed to be digestible in a process similar to the one described in NREL's biochemical ethanol design report (Humbird et al. 2011). Off-gas from the digester is routed to the hydrogen plant. The process was modeled as a stoichiometric reactor with complete conversion to $\mathrm{CO}_{2}$ and $\mathrm{CH}_{4}$.

Steam and power: Off-gases that are not needed for hydrogen generation are sent to a boiler for combustion to generate superheated steam. Steam not utilized in the process is sent for power generation in a turbine system.

\section{Data Gaps, Uncertainties, and Research Needs}

The majority of the model is literature based and there may be little or no new data available in the next year. The goal of this pathway is to reach a minimum fuel selling price of $\$ 3 /$ gallon of gasoline equivalent (in 2011 U.S. dollars). To reach this targeted product price, the key bottlenecks, uncertainties, and areas for further development are summarized as follows:

- Demonstrate and optimize yield. Most of the literature data is based on ex-situ-type processing where pyrolysis vapors from the cyclone are upgraded in a separate reactor. There is very little data in the literature regarding pyrolysis combined with upgrading in a single vessel. Processing costs, organic losses to the aqueous phase, and extent of upgrading were estimated based on ex-situ processing. Coke production may be significant. The primary goal in optimizing this process is to retain as much carbon in the liquid product as possible while removing the highly reactive oxygen species.

- Develop reactor design data. Little is known about the design and operation of the catalytic pyrolysis reactor. Research is needed to understand issues such as the effect of 
biomass residence time, catalyst residence time, and the biomass-to-catalyst ratio, each of which is likely important for both performance and economics. It is also not known if an inert heat carrier, such as sand, will be needed. Heat and mass transfer effects need to be researched through experimental efforts on a continuous system consistent with the assumed design. Careful design of the product recovery scheme is needed to ensure product stability and mitigate fouling. Handling large amounts of solids will also need attention. Effective removal of solids is necessary to ensure no negative effects on downstream integration.

- Develop and optimize pyrolysis catalyst. Catalyst maintenance and stability are unknown, as are regeneration protocols and lifetime. Mineral and carbon deposits may be difficult to remove. Testing with biomass and detailed characterization of catalyst performance and deactivation modes are needed. Catalysts developed for this process need to be both mechanically and thermally stable and robust to improve overall lifetimes. The catalyst must produce a catalytic pyrolysis oil product that is an improvement over conventional pyrolysis oil, and that oil must be produced in good yield. A fundamental understanding of the detailed reaction mechanisms and kinetics can enable the design of catalysts with optimal productivity rates and yields toward desired product slates. Investigating the solid/vapor interface chemistry and increasing the catalytic conversion will be key for catalyst improvements. Rational design and development of catalysts could be accomplished using a combination of computational and experimental techniques.

- Optimize hydrotreating. Hydrodeoxygenation upgrading may be performed in a single bed if the catalytic pyrolysis oil is of sufficiently low oxygen content or if the oxygen is contained within relatively unreactive species that do not readily polymerize. Parameter testing and development of compounds' structure-reactivity relationships are needed. Hydrodeoxygenation catalyst maintenance issues are unknown but should be easier to manage than processing raw fast pyrolysis oil. Long term catalyst testing, upgraded biooil speciation, and fuel quality tests are needed. There is a need to understand mass transfer issues of hydrogen in bio-oil and on the catalyst, as well as to determine how alkenes, aromatics, and oxygenates affect hydrogen usage.

- Characterize fuels and intermediates. The final hydrocarbon products may not be of sufficient quality to use as a blendstock, which was assumed in the economics. Key properties such as cetane and octane, as well as flash points, smoke points, cloud or pour points, and distillation curves must be verified against gasoline and diesel specifications. Consideration should be given to production of refinery intermediates instead of finished fuels, and as such, better characterization of the catalytic pyrolysis oil is needed. The offgas composition should also be better characterized to verify its suitability as a hydrogen plant feedstock.

- Establish optimum catalytic pyrolysis oil properties. A key part of the process design will be developing an understanding of effective process integration, specifically the trade-offs between the amount and quality of oil produced via catalytic pyrolysis and the impact this has on downstream hydrodeoxygenation. Higher quality oil requires less hydrodeoxygenation but the yield may be reduced from the catalytic pyrolysis step. 
Lower quality oil will require higher severity hydrodeoxygenation but also may have higher yields.

- Determine optimum wastewater treatment. Wastewater treatment is largely unexplored, and anaerobic digestion may not be appropriate for the types of species present. There is a need to understand the impact of organic compounds on wastewater treatment, to understand the toxicity of trace compounds, and to minimize carbon loss to wastewater treatment. Research is needed to understand the conversion of organics in the aqueous phase to hydrogen, bio-products, and species that can rejoin the predominately organic phase. Consideration should also be given to alternate wastewater treatment methods such as catalytic hydrothermal gasification.

\section{Summary and Next Steps}

This study assessed the processing of woody biomass conversion via in-situ catalytic fast pyrolysis followed by upgrading and finishing to gasoline-, diesel-, and jet-range hydrocarbon blendstocks. A literature-based techno-economic analysis was performed to identify technology gaps, uncertainties, and research needed to achieve a minimum fuel selling price of $\$ 3 /$ gallon of gasoline equivalent. A design case detailing this pathway will be developed in FY14.

\section{References}

Agblevor, F.; Mante, O.; Abdoulmoumine, N.; McClung, R. (2010). "Production of Stable Biomass Pyrolysis Oils Using Fractional Catalytic Pyrolysis.” Energy \& Fuels (24); pp. $4087-$ 4089.

Czernik, S. (2011). "Catalytic Pyrolysis of Biomass at NREL." Presented at TC Biomass 2011, Chicago, Illinois, September 27-30, 2011.

Dayton, D. (2011a), “Catalytic Biomass Pyrolysis for Bio-Crude Production: Catalyst Screening and Process Development." Presented at TC Biomass 2011, Chicago Illinois, September 27-30, 2011.

Dayton, D. (2011b). "Catalytic Deoxygenation of Biomass Pyrolysis Vapors to Improve Bio-Oil Stability." Presented at the 2011 DOE/OBP Thermochemical Platform Review, February 16, 2011.

Dutta, A.; Talmadge, M.; Hensley, J.; Worley, M.; Dudgeon, D.; Barton, D.; Groendijk, P.; Ferrari, D.; Stears, B.; Searcy, E. M.; Wright, C. T.; Hess, J. R. (2011). Process Design and Economics for Conversion of Lignocellulosic Biomass to Ethanol: Thermochemical Pathway by Indirect Gasification and Mixed Alcohol Synthesis. NREL/TP-5100-51400. Golden, CO:

National Renewable Energy Laboratory.

Elliott, D.; Hart, T.; Neuenschwander, G.; Rotness, L.; Zacher, A. (2009). “Catalytic Hydroprocessing of Biomass Fast Pyrolysis Bio-Oil to Produce Hydrocarbon Products.” Environmental Progress \& Sustainable Energy (28:3); pp. 441-449.

Humbird, D.; Davis, R.; Tao, L.; Kinchin, C.; Hsu, D.; Aden, A.; Schoen, P.; Lukas, J.; Olthof, B.; Worley, M.; Sexton, D.; Dudgeon, D. (May 2011). Process Design and Economics for 
Biochemical Conversion of Lignocellulosic Biomass to Ethanol: Dilute-Acid Pretreatment and Enzymatic Hydrolysis of Corn Stover. NREL/TP-5100-47764. Golden, CO: National Renewable Energy Laboratory.

Jones, S.; Valkenburg, C.; Walton, C.; Elliott, D.; Holladay, J.; Stevens, D.; Kinchin, C.; Czernik, S. (February 2009). Production of Gasoline and Diesel from Biomass via Fast Pyrolysis, Hydrotreating and Hydrocracking: A Design Case. PNNL-18284. Richland, WA: Pacific Northwest National Laboratory.

Jones, S.; Male, J. (2012). Production of Gasoline and Diesel from Biomass via Fast Pyrolysis, Hydrotreating and Hydrocracking: 2011 State of Technology and Projections to 2017. PNNL 22133. Richland, WA: Pacific Northwest National Laboratory.

Mante, O.; Agblevor, F. (2011). "Catalytic Conversion of Biomass to Bio-Syncrude Oil." Biomass Conversion and Biorefinery (1); pp. 203-215.

SRI Consulting. (2007). PEP Yearbook. Menlo Park, CA: SRI Consulting. http://www.sriconsulting.com/.

Stefanidis, S.; Kalogiannis, K.; Iliopouulou, E.; Lappas, A.; Pilavachi, P. (2011). "In-situ Upgrading of Biomass Pyrolysis Vapors: Catalyst Screening on a Fixed Bed Reactor." Bioresource Technology (102); pp. 8261-8267.

Zacher, A.; Santosa, D.; Elliott, D. Brown, C.; Beckman D. (2011). "Mild Catalytic Fast Pyrolysis of Biomass and Catalytic Hydrotreating to Liquid Transportation Fuels." PNNL-SA82908. Presented at TC Biomass 2011, Chicago Illinois. 